\section{Examining teamwork competencies and team performance in experiential entrepreneurship education: emergent intragroup conflict as a learning triggering event}

Teamwork competencies and team performance

\author{
Pilar Pazos
}

Old Dominion University, Norfolk, Virginia, USA, and

María Carmen Pérez-López and María José González-López

University of Granada, Granada, Spain

\begin{abstract}
Purpose - Although the importance of teamwork competencies and effective conflict management in entrepreneurship education is recognised, we have limited knowledge of how these factors interact to influence performance in entrepreneurial teams. This research explores teamwork competencies as a predictor of entrepreneurial team performance and the moderating effect of emerging cognitive and interpersonal team conflict as levers in entrepreneurship learning.

Design/methodology/approach - A time-lagged survey method was used to collect data from 49 teams (156 individuals) of undergraduate students in an experiential new venture creation course. A predictive model of entrepreneurial team performance through hierarchical regression analyses and moderated-moderation analyses was tested.

Findings - Results reveal that teamwork competencies have a significant and direct influence on entrepreneurial team performance and that intragroup conflict strengthens that relationship when high levels of cognitive conflict and low levels of interpersonal conflict emerge.

Practical implications - The findings have implications for the design of entrepreneurial training programs, which will benefit from interventions aimed at teamwork competency development that incorporate strategies promoting constructive cognitive conflict while preventing the emergence of interpersonal conflict.

Originality/value - This study is a step forward in entrepreneurship education research from the perspective of social and interpersonal processes by identifying the patterns of intra-team conflict that lead to more effective entrepreneurial teams and more productive use of teamwork competencies in a learning-by-doing entrepreneurial context.
\end{abstract}

Keywords Entrepreneurship education, Entrepreneurial teams, Teamwork competencies, Cognitive conflict, Interpersonal conflict

Paper type Research paper

\section{Introduction}

Academics and policymakers widely recognise entrepreneurship education as a vehicle to promote new venture development and advance critical competencies to thrive in complex, interdependent, and dynamic environments (Birdthistle et al., 2016; Peschl et al., 2021). From

(C) Pilar Pazos, María Carmen Pérez-López and María José González-López. Published by Emerald Publishing Limited. This article is published under the Creative Commons Attribution (CC BY 4.0) licence. Anyone may reproduce, distribute, translate and create derivative works of this article (for both commercial and non-commercial purposes), subject to full attribution to the original publication and authors. The full terms of this licence may be seen at http://creativecommons.org/licences/by/4.0/ legalcode.

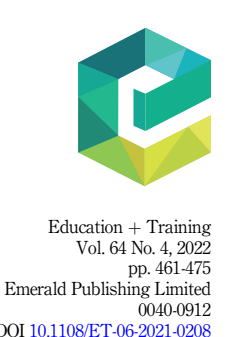

DOI 10.1108/ET-06-2021-0208 
the theoretical perspective of constructivism and pragmatic educational approaches (Kolb, 1984), there is a wide consensus that entrepreneurship education programs should build upon experiential and action-oriented theories and pedagogies (Bell and Bell, 2016; Hägg and Gabrielsson, 2020; Lackéus, 2020; Kozlinska et al., 2020). Based on this perspective, the entrepreneurial learning that takes place during new venture creation can be simulated through experiential and collaborative educational interventions (Pittaway and Cope, 2007). In this context, experiential entrepreneurship education is defined as a form of participative learning that seeks to emulate the contexts faced by entrepreneurs by having students interact with potential customers, partners and suppliers to identify and develop a business opportunity while practicing and developing their entrepreneurial competencies (Mandel and Noyes, 2016; Morland et al., 2021). These approaches to entrepreneurship education programs usually involve students working in teams. Teamwork is, therefore, an essential part of this methodology that contributes to effective entrepreneurship education and deeper learning (Harms, 2015; Lackéus, 2020; Weber and Funke, 2012).

Teamwork competencies, defined as the knowledge, skills and abilities (KSAs) required to work effectively in a team (Stevens and Campion, 1999), can play an essential role in the success of project-based approaches in entrepreneurship education (Bauman and Lucy, 2019; Harms, 2015; Hwang, 2018). Notably, the early stages of business ideation and planning involve idea generation, decision making and problem solving, which benefit from collaboration and synergy to achieve an innovative shared vision and a viable business model (Knipfer et al., 2018). The way in which entrepreneurial team members work together affects the development of entrepreneurial drive and can influence new ventures' performance and financial results (Brinckmann and Hoegl, 2011; Chen et al., 2017). However, few research studies have examined entrepreneurial education settings to determine whether teams with specific teamwork competencies are more likely to thrive in the challenging and uncertain context of entrepreneurship. More specifically, we have limited understanding of the impact of teamwork competencies during the early stages of entrepreneurship in which creativity and innovation are key and financial measures of performance are not discernible yet (Foo et al., 2006; Hwang, 2018). Thus, this study's first goal is to uncover the effect of teamwork competencies on the performance of entrepreneurial teams in an experiential entrepreneurship education course.

The relationship between the competencies and team performance can be further influenced by emergent states that reflect cognitive and affective properties of team interaction (Barrick et al., 2007; DeChurch et al., 2013). Creative and innovative tasks, such as those undertaken by entrepreneurial teams in experiential entrepreneurship education programs, are based on the team's ability to generate diverse ideas and perspectives reflective of high levels of cognitive conflict (Zhou and Verburg, 2020). As teams become increasingly exposed to rich and diverse ideas through emerging cognitive conflict, they will need to rely on teamwork competencies such as communication, decision making and problem solving to channel these different perspectives into an inclusive, goal-oriented, efficient and productive interaction (Brinckmann and Hoegl, 2011). From this perspective, emerging cognitive conflict can act as a learning catalyst in teams by driving students to use teamwork competencies as they engage in the collaborative problem solving and consensus building activities needed to resolve cognitive dissonance and reach the objective of the entrepreneurial course projects (Chen et al., 2021; Hero and Lindfors, 2019). In response to the call for additional research on the interplay between team member characteristics, emerging conflict and team performance in learning-by-doing entrepreneurial education settings (Chen et al., 2021; Maltarich et al., 2018), the second goal of this study is to determine whether increased levels of cognitive conflict strengthen the relationship between teamwork competencies and entrepreneurial team performance through a positive moderation effect.

Relationship conflict is another important and often disrupting emergent state that reflects the levels of interpersonal tension stemming from people's interaction in a team 
(DeChurch et al., 2013). When teams face an environment of high interpersonal conflict, they are more likely to lose focus on the task as they render their cognitive resources to deal with the emotional tension, thereby reducing their ability to process information associated with the task. Few studies have looked at how cognitive and interpersonal conflict levels amplify or weaken the relationship between team competencies and team outcomes (Costa et al., 2015; Mazra, 2017). Thus, the third goal of this research is to examine how the interaction of interpersonal and cognitive conflict affects the relationship between team competencies and entrepreneurial team performance.

This study contributes to research in entrepreneurship education in two areas. First, we provide evidence of how teamwork competencies (measured through an objective situational test) relate to team performance in an experiential entrepreneurship course. Second, this study's findings contribute to understanding socio-cognitive phenomena in entrepreneurial teams by examining how cognitive and interpersonal conflict can affect the relationship between teamwork competencies and performance and by identifying the conditions under which conflict can be more conducive to entrepreneurial team performance.

\section{Literature review and research hypotheses}

\subsection{Teamwork competencies and entrepreneurial team performance}

Human capital theory predicts that the level of competencies possessed by individuals or groups is predictive of their level of performance (Becker, 1964). Prior research shows that knowledge, skills and abilities related to goal setting, planning, tasks coordination, conflict resolution, collaborative problem solving, communication and performance management (Stevens and Campion, 1999) predict team effectiveness across a variety of contexts (Mathieu et al., 2014; Salas et al., 2018), included that of new ventures teams' performance (Brinckmann and Hoegl, 2011; Chen et al., 2017).

Experiential entrepreneurship education settings often require student teams to engage in authentic entrepreneurial activities that use these competencies to set goals, communicate, negotiate and develop innovative and valuable solutions to real-world problems or challenges (Hero and Lindfors, 2019; Lackéus, 2020). Although teamwork competencies are considered key in entrepreneurial learning (Bauman and Lucy, 2019; Hero and Lindfors, 2019), empirical studies exploring teamwork competencies as an antecedent of entrepreneurial team performance are scarce in entrepreneurial education contexts (Hwang, 2018). Prior research by Chang and Lee (2013) found that certain dimensions of teamwork competencies, such as conflict management skills, improve learning performance in business planning education programs. Similarly, Knipfer et al. (2018) concluded that during the pre-founding phase, which is reflected in most entrepreneurship projects in education, the way in which teams work together is key in leveraging performance. However, the impact of a broad set of teamwork competencies on entrepreneurial team performance is not well understood. This study examines the relationship between teamwork competencies and entrepreneurial team performance in an experiential entrepreneurship education context through the following hypothesis:

H1. There is a positive relationship between teamwork competencies (KSAs) and entrepreneurial team performance.

\subsection{The role of intragroup conflict in the teamwork competencies-performance link}

Research examining experiential project-based approaches using teams shows that these pedagogical approaches trigger emotional learning events leading to enhanced learning outcomes in entrepreneurship education (Lackéus, 2020). One of the most critical emotional challenges students face when working in teams stems from the conflicts that can emerge

\section{Teamwork competencies and team performance}


(Neumeyer and Santos, 2020). Intra-team conflict is defined as a state that reflects a representation of the level of interpersonal tension with people in the team (relationship conflict) and the level of disagreement on how to approach the task at hand (cognitive conflict) (DeChurch et al., 2013).

Although high and unmanaged levels of conflict in student teams can harm performance (Neumeyer and Santos, 2020; Wang et al., 2019), some conflict can also enhance learning and overall team performance by motivating students to engage in collaborative activities that require them to contrast and reconcile opinions and conduct a comprehensive evaluation of solutions in entrepreneurship (Chen et al., 2021; Hero and Lindfors, 2019). Managing the cognitive dissonance associated with conflict of ideas requires strong communication, cognition and consensus-building skills in the team to achieve superior performance (Mitchell et al., 2019). Therefore, the successful management of emerging conflict in a team relies on its members' interpersonal and conflict management skills (Bissola et al., 2017; Leffel et al., 2016).

There is growing interest in examining the interaction between individual characteristics in entrepreneurial teams, intra-team conflict and outcomes of the entrepreneurial process (Wang et al., 2019). Recent studies propose the role of intra-team conflict as a moderator that can enable or disrupt the relationships between team characteristics and team outcomes (Costa et al., 2015; Mazra, 2017; Mitchell et al., 2019). Furthermore, studies in the field of entrepreneurial learning provide empirical evidence that teams exposed to higher levels of cognitive conflict experience more diverse opinions about the task at hand and are more likely to use their resources (knowledge and skills) effectively to achieve a successful outcome (Boyle et al., 2012; Martínez-Moreno et al., 2009). This study proposes the operationalisation of cognitive conflict as a learning event that strengthens the relationship between teamwork competencies and performance during the early stages of business ideation in the context of entrepreneurship education. Thus, we propose the following hypothesis:

H2. As a team's cognitive conflict increases, it strengthens the positive relationship between teamwork competencies (KSAs) and entrepreneurial team performance.

As entrepreneurial teams engage in collaborative processes to accomplish a task, interpersonal conflict can emerge from the interaction and potentially interfere with the team's cognitive and behavioural processes to influence outcomes (De Wit et al., 2012). Cognitive and interpersonal conflicts are known to interact with each other to influence team performance in complex ways, whereby the benefits of engaging in cognitive conflict can dwindle as levels of interpersonal conflict rise (De Dreu and Weingart, 2003; De Jong et al., 2013).

Information processing theory has been used to examine the relationships between conflict profiles, cognitive resources and performance in teams (e.g. Shaw et al., 2011). When facing high interpersonal conflict, teams tend to withdraw cognitive resources from value added processes to dedicate them to manage off-task and emotionally charged issues that do not add value to the team's performance (Porath and Erez, 2007). Such events cause process interferences, reducing the entrepreneurial team's ability to consider and examine ideas or evidence and thereby eroding the potential benefits of cognitive conflict (Wang et al., 2019).

There is little understanding of the combined effect of cognitive and interpersonal conflict on the team's ability to utilise their competencies to accomplish their goals. Costa et al. (2015) found a positive moderating effect of cognitive conflict in the relationship between team resources and teamwork engagement and a negative moderating effect of interpersonal conflict in the relationship between teamwork engagement and team performance. They argue that relationship conflict interferes with the collaboration process and negatively affects the team's engagement. In contrast, constructive discussions of ideas positively influence the team's engagement and promote increased levels of performance. In the context of new venture teams, Mazra (2017) identified parallel and competing effects of both types of 
conflict on the relationship between competency diversity (including skills and experience) and performance, with cognitive conflict acting as a positive moderator and relationship conflict having the opposite effect.

This study proposes that the relationship between teamwork competencies and team performance will vary conditional on the types of conflict profiles that emerge in the team. High levels of interpersonal conflict can interfere with the collaborative learning processes involved in new venture ideation and planning, driving the team's cognitive resources away from the task at hand to deal with the interpersonal tensions. Hence, the teams will be less likely to use their teamwork competencies to achieve their outcomes, countering cognitive conflict's positive moderating effect. Thus, the following hypothesis is proposed:

H3. As interpersonal conflict increases, it weakens the positive moderation effect of cognitive conflict on the teamwork competencies (KSAs) - team performance relationship.

Figure 1 illustrates the proposed hypotheses.

\section{Methodology}

\subsection{Entrepreneurship education context}

This study aimed to maximise the fidelity of entrepreneurial education activities while maintaining some experimental control over the nature and scope of the task and the characteristics of the teams involved. The proposed setting uses a new business development course with an action-oriented and experiential learning approach where student teams work on authentic business development projects.

Each student team had to identify an authentic problem or market opportunity and develop a new venture project to address it by creating solutions with social and/or economic value. Using design thinking processes to develop their business idea, teams were required to contact potential investors, users and other stakeholders to develop a deeper understanding of the needs and motivations associated with the problem or opportunity, to define a value proposition and to test the business model hypotheses and prototypes (Boni et al., 2009). Student teams were also expected to prepare business plans where they analysed the strategy of their project and assess its technical, commercial and financial viability (Chwolka and Raith, 2012). Both design thinking and business planning promote the emergence of cognitive conflict and contribute to a team-based learning process (Boni et al., 2009; Kollmann et al., 2019). Participating faculty acted as mentors or coaches during the learning process.

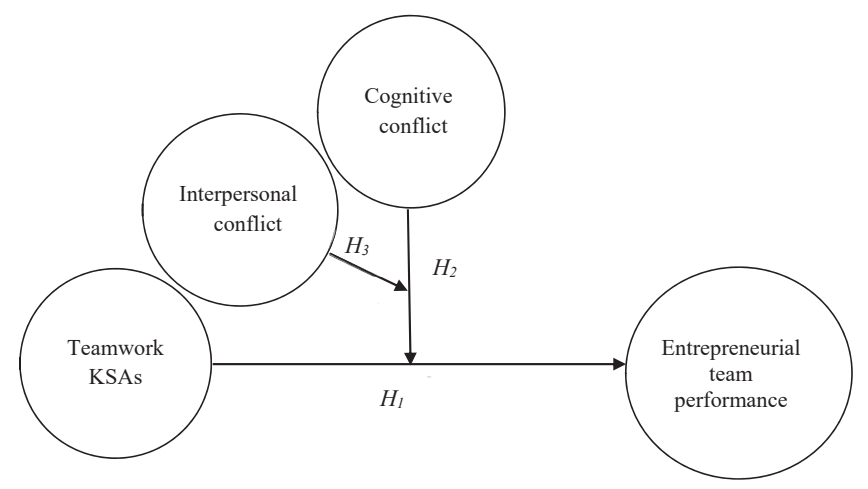

Figure 1. Proposed research hypotheses

\section{Teamwork competencies and team performance}


This study uses time-lagged data from undergraduate students from a business school at a Spanish university. One hundred fifty-six undergraduate students self-selected into 49 teams ranging in size between three and five. Participants had an average age of 22.3 years $(S D=1.86)$, and $59.6 \%$ were women. Study data comes from surveys completed by the students at the start and the end of the academic semester. Teamwork competencies were measured before forming the teams. Cognitive and interpersonal conflict were measured at the end of the entrepreneurship project so that students could assess the overall emergence of conflict throughout the project. Entrepreneurial team performance was assessed after the submission of all final deliverables and presentations. Applying these time lags between the measurements and collecting data from different sources (team members and subject matter experts) allows a more reliable causal interpretation of the relationships found and helps to avoid confounding effects such as common method bias (Podsakoff et al., 2003).

\subsection{Measures}

3.3.1 Teamwork competencies. The Teamwork-KSA instrument, developed by Stevens and Campion (1999), was used to evaluate team members' teamwork competencies (knowledge, skills and abilities). It is a situational judgment test, including 35 multiple choice questions representing hypothetical teamwork situations that encompass both interpersonal and selfmanagement competencies. Each question has four answers with only one correct, resulting in a dichotomous variable $(0,1)$. The test score is the sum of all correct answers, and it ranges from 0 (no correct answers) to 35 (all correct answers). This test has been previously used to measure teamwork KSAs in student teams (e.g. Chen et al., 2004; Miller, 2001; Weber and Funke, 2012). The test presents a Cronbach's alpha of 0.64 , which has been considered acceptable given that the inherent internal consistency reliability of situational judgment tests is limited by the dichotomous nature of its data, which makes traditional psychometric thresholds very restrictive (Sorrel et al., 2016). Prior studies using this instrument had similar, although slightly lower, levels of reliability like Weber and Funke (2012) with 0.56 or McClough and Rogelberg (2003) with 0.59.

3.3.2 Conflict. The two dimensions of conflict examined in this study (cognitive and interpersonal) are measured using the Intragroup Conflict Scale developed by Jehn (1995) and later validated and refined by Pearson $e t$ al. (2002). This scale includes six items scored on a 5point Likert scale, with two subconstructs for cognitive and interpersonal conflict of three items each. The reliability (Cronbach's alpha) of the interpersonal conflict scale was 0.91 , and for the cognitive conflict scale, it was 0.71 . The measures of interpersonal conflict and cognitive conflict at the team level consist of an aggregate of the individual-level measures. As suggested by Chen et al. (2004), the validity of the aggregated measure was tested using $r_{w g}$. Results from this analysis showed strong agreement for both interpersonal conflict $\left(r_{w g}=0.84\right)$ and cognitive conflict $\left(r_{w g}=0.76\right)$, with values beyond the recommended threshold of 0.7 (Cohen et al, 2001).

3.3.3 Entrepreneurial team performance. The entrepreneurial team performance measure combines the team's score in the project deliverable and presentation evaluated by multiple stakeholders, including the instructor, a group of subject matter experts and teammates. The assessment incorporates intermediate milestones, including the application of the design thinking methodology, a business model definition and validation, a business development activity blog and a business plan. In line with Knipfer et al. (2018) and Neumeyer and Santos (2020), the business solution proposed by the teams was evaluated using a rubric assessing several aspects of the project, including novelty, feasibility, market potential, effectiveness, efficiency and quality of the business planning process. The final performance can take values between 1 (very poor) and 10 (outstanding).

3.3.4 Control variables. In addition, we include two team characteristics that are known to influence entrepreneurial teams' performance, namely, gender diversity and teamwork 
experience (Hoogendoorn et al., 2013; Huber et al, 2020). Gender diversity was measured as the percentage of women on the team. Teamwork experience was measured using a binary variable, taking the value 1 when the individual has previous teamwork experience and 0 otherwise.

\subsection{Statistical analysis}

Hierarchical regression analysis was used to test the proposed hypotheses in Figure 1. Model 1 tested the effects of each of the independent variables (teamwork KSAs, cognitive conflict and interpersonal conflict) and entrepreneurial team performance controlling for gender diversity and teamwork experience. Model 2 incorporated the second-level interactions to investigate the moderating role of cognitive conflict on the relationship between teamwork KSAs and entrepreneurial team performance. Model 3 incorporates all the second-level interactions and the three-level interaction factor to test Hypothesis 3, which will determine whether there is a moderated moderation relationship whereby interpersonal and cognitive conflict interact to influence the relationship between teamwork KSAs and entrepreneurial team performance. In the proposed theoretical model, cognitive conflict is the primary moderator, and interpersonal conflict is the secondary moderator (see Figure 1). The three-way interaction was further examined using the PROCESS macro for SPSS version 26 (Hayes, 2018). This analysis used Model 3 for moderated moderation (95\% bias-corrected bootstrapping with 5,000 resamples).

\section{Results}

Table 1 outlines the descriptive statistics of the sample, including means, standard deviation and correlations.

Table 2 includes the results of the hierarchical regression analysis. Model 1, which includes only the main effects, accounts for $23 \%$ of entrepreneurial team performance variance. Results show a statistically significant relationship between teamwork KSAs and entrepreneurial team performance $(\beta=0.405, p<0.05)$, supporting Hypothesis 1 . Model 2 improved the explanatory power of Model 1 from $23 \%$ to $31 \%$. The two-way interaction effect of cognitive conflict on the relationship between teamwork KSAs and performance was, as predicted, positive $(\beta=0.376, p<0.05)$, which supports Hypothesis 2 .

Model 3 explains an additional $8 \%$ of team performance variance, which provides the most optimal fit to the data. The results of the three-way interaction between KSA*CC*IC $(\beta=0.755, p<0.05)$ suggest that the magnitude of the moderation by cognitive conflict of the teamwork KSAs-team performance varies based on the level of emerging interpersonal conflict in the team, which supports Hypotheses 3.

Given the significance of the three-way interaction, additional analysis using the PROCESS macro was conducted to examine the moderated moderation effect. The analysis further supported the statistical significance of the moderated moderation effect $\beta=0.74$; $p<0.05)$. The analysis revealed that the relationship between teamwork KSAs and performance changes as we move along the cognitive conflict and the interpersonal conflict continuum through a three-way interaction. The nature of the moderated moderation effect was further analysed through a slope difference test of the three-way interaction of teamwork

\begin{tabular}{lrrrrrrrr}
\hline Variables & Mean & \multicolumn{1}{c}{$S D$} & 1 & 2 & 3 & 4 & 5 & 6 \\
\hline 1. Performance & 7.77 & 1.13 & 1 & & & & & \\
2. Teamwork KSAs & 16.38 & 2.68 & $0.444^{* *}$ & 1 & & & & \\
3. Cognitive conflict & 3.41 & 0.96 & $-0.299^{*}$ & -0.171 & 1 & & & \\
4. Interpersonal conflict & 2.32 & 1.19 & -0.175 & -0.133 & $0.703^{* *}$ & 1 & & \\
5. Gender diversity & 0.63 & 0.33 & 0.186 & 0.130 & $-0.326^{*}$ & -0.191 & 1 & \\
6. Team experience & 0.95 & 0.13 & 0.229 & 0.224 & -0.140 & 0.152 & 0.208 & 1
\end{tabular}

Note(s): ${ }^{*} p<0.05 ;{ }^{* * *} p<0.01$ SD: Standard deviation
Teamwork competencies and team performance

467

\section{$-$}




\begin{tabular}{|c|c|c|c|c|}
\hline \multirow{2}{*}{$\begin{array}{l}\text { ET } \\
64,4\end{array}$} & \\
\hline & Dependent variable & Model 1 & $\begin{array}{r}\text { urial team } \\
\text { Model } 2\end{array}$ & Model 3 \\
\hline \multirow[b]{5}{*}{468} & Teamwork KSAs (KSA) & $0.405^{*}$ & $0.359^{*}$ & 0.109 \\
\hline & Cognitive conflict (CC) & -0.286 & -0.146 & -0.007 \\
\hline & Interpersonal conflict (IC) & 0.080 & -0.004 & -0.160 \\
\hline & $\mathrm{KSA}^{*} \mathrm{CC}$ & & $0.376^{*}$ & $0.610^{* * *}$ \\
\hline & KSA*IC & & -0.250 & $-0.598^{*}$ \\
\hline \multirow{7}{*}{$\begin{array}{l}\text { Table } 2 \text {. } \\
\text { Results from } \\
\text { hierarchical regression } \\
\text { models }\end{array}$} & $\begin{array}{l}\mathrm{CC} * \mathrm{IC} \\
\mathrm{KSA}{ }^{*} \mathrm{CC} * \mathrm{IC}\end{array}$ & & 0.013 & $\begin{array}{l}0.522 \\
0.755^{*}\end{array}$ \\
\hline & Teamwork experience & 0.058 & 0.055 & 0.043 \\
\hline & Gender diversity & 0.103 & 0.048 & -0.032 \\
\hline & $R^{2}$ & 0.231 & 0.309 & 0.390 \\
\hline & $F$-statistic & 2.520 & 2.239 & 2.711 \\
\hline & $p$-value & 0.044 & 0.045 & 0.013 \\
\hline & \multicolumn{4}{|c|}{ Note(s): The table displays the standardised regression coefficients; ${ }^{* *} p<0.01 ;{ }^{*} p<0.05$} \\
\hline
\end{tabular}

KSA*CC*IC. The slopes in Figure 2 display the value and direction of the relationship between teamwork KSAs and performance for different combinations of cognitive conflict and interpersonal conflict.

As shown in the left graph of Figure 2, the relationship's slope remains positive for low levels of interpersonal conflict regardless of the level of cognitive conflict. Thus, teams seem to translate teamwork competencies into better performance when cognitive conflict is high and interpersonal conflict is low. On the other hand, when interpersonal conflict is high (Figure 2right), the relationship between teamwork KSAs and performance becomes negative for low and medium cognitive conflict levels. Under these conditions, team members are focusing their cognitive resources to deal with interpersonal conflict, so even if they have strong competencies, those are not being used to contribute to the ideation and planning processes. The results suggest that when teams face high interpersonal conflict levels, it can counter the positive moderating effect of cognitive conflict unless their cognitive conflict levels are high.

\section{Discussion}

This study offers new insights into the relationships between teamwork competencies, team conflict and team performance in entrepreneurship education. Firstly, with regards to the study of teamwork competencies, this research provides a unique perspective by using an assessment of team competencies based on a situational judgment test considered more objective than more widely used self-reported metrics of prior studies (O'Neill et al., 2013; Steven and Campion, 1999), which are subject to social desirability bias (Weber and Funke, 2012). The positive association between teamwork KSAs and performance in entrepreneurial student teams found in this study is consistent with prior studies of work teams in field settings (Leach et al., 2005; Stevens et al., 2002; Stevens and Campion, 1999) and in the context of self-managing teams (Doblinger, 2022; Hirschfeld et al., 2006).

In academic settings, there is contradictory evidence about the relationship between Stevens and Campion's measure of KSAs and team performance. For instance, Tasa et al. (2007), in a study with business students immersed in a human resource management simulation, found that teamwork KSAs were indirectly associated, through increased collective efficacy, with higher team performance. In contrast, a study with management students using an organisational simulation, found no relationship between teamwork KSAs and team project performance (Miller, 2001). A plausible explanation of the difference in findings is that the nature of the task could have influenced the teamwork KSA performance link such that tasks that involve little task variety and task interdependence may preclude 


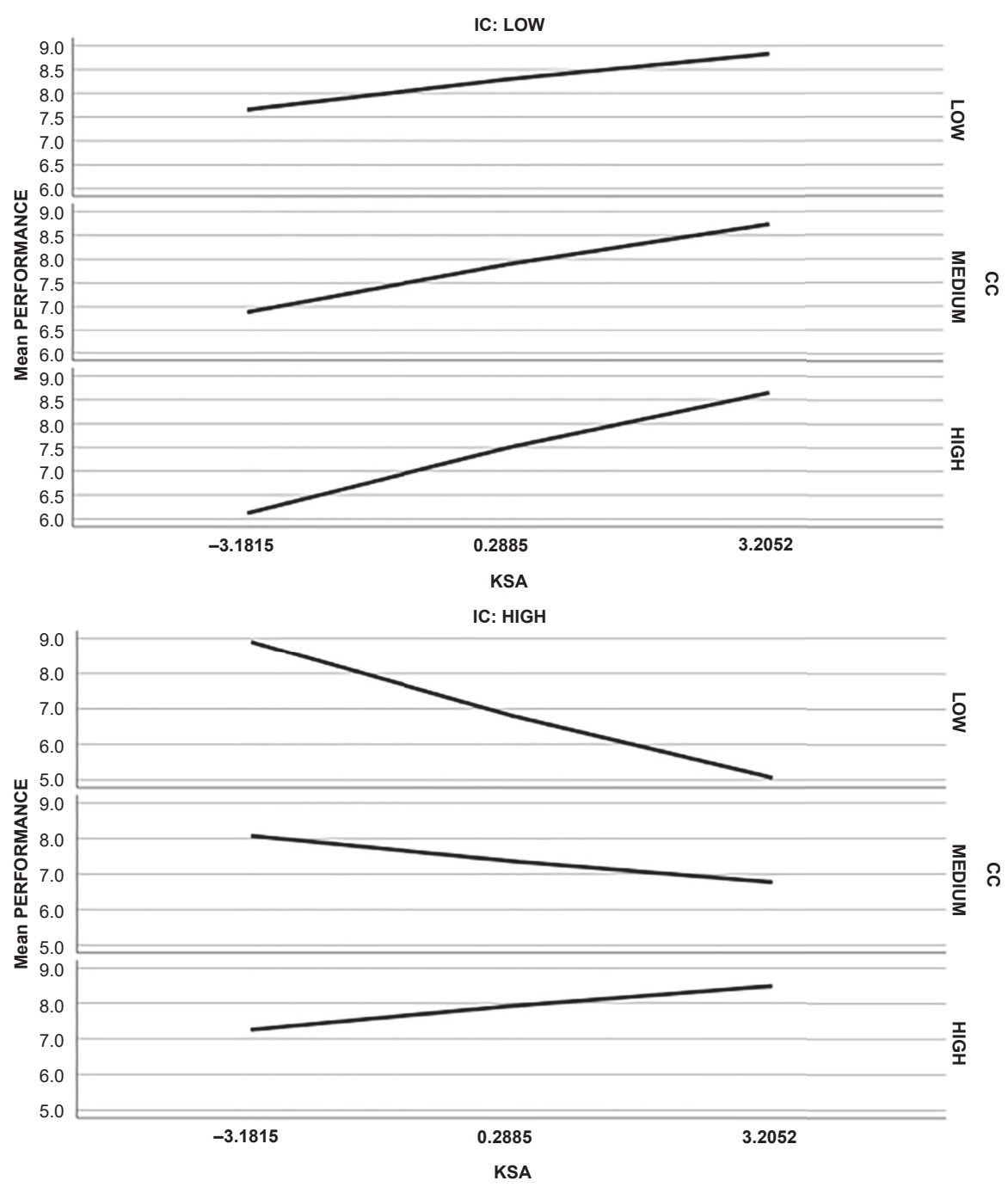

students from using teamwork skills to their full potential. In our study, students had to accomplish a variety of complex interdependent tasks that required them to interact with a wide range of stakeholders, including industry experts, customers and entrepreneurs. It is likely that these heightened levels of complexity and interdependence call for increased applicability of teamwork skills. Other studies that have used the teamwork KSA test to assess team competencies the field of business education reveal their positive effect on team behaviours measured at the individual level (McClough and Rogelberg, 2003). The current study complements this previous work by showing how teamwork competencies positively drive team performance outcomes during experiential new venture creation projects.

Secondly, the context used for this study facilitates the examination of the association between team competencies and team outcomes that are proximal to the early stages of the 
entrepreneurial process. Prior research has mostly focused on more distal outcomes such as financial or business performance indicators (Baron and Tang, 2009; Brinckman and Hoegl, 2011). This study offers a new perspective on the importance of teamwork competencies on entrepreneurial performance by incorporating metrics that capture the critical early stages of the new venture development, such as opportunity recognition, business ideation and business planning.

Thirdly, although prior research exploring the impact of cognitive conflict in entrepreneurship contexts reveal contradictory findings (for example, Foo, 2011; Hülsheger et al., 2009), some researchers propose that as levels of cognitive conflict increase, teams must rely on teamwork competencies in order to produce innovative and effective solutions (Boyle et al., 2012; Martínez-Moreno et al., 2009). This study further explored this proposition empirically by examining the interaction between teamwork competencies and cognitive conflict and their influence on entrepreneurial team performance. Results indicate that as entrepreneurial teams engage in increased cognitive conflict, they are more likely to rely on teamwork competencies to manage cognitive disagreements and produce higher quality learning outcomes. Consequently, teams with highly skilled members at collaboration were more effective at translating divergent cognitive conflict into convergent solutions. Our findings complement a recent line of research examining the moderating role of conflict in the relationship between teamwork competencies and performance by expanding into entrepreneurial teams (Hu et al., 2019; Mitchell et al., 2019) and also reveal the positive role of emergent cognitive conflict as a learning event in experiential entrepreneurship education programs that promotes better learning outcomes.

This study's findings expand on previous research on the effects of conflict in new venture team's performance. Mazra (2017) found that in new venture teams, diversity of skills and experience have a positive impact on the performance of the business venture. Our study expands on Mazra's by examining the combined impact of teamwork skills and emerging conflict on the performance of the team in entrepreneurship education. Our results reveal that the positive relationship between team competencies on team performance varies in intensity depending on the level of cognitive conflict. Additionally, this positive relationship can change direction in contexts that combine high levels of interpersonal conflict with mid to low levels of cognitive conflict. There is evidence of an indirect effect of interpersonal conflict that was more likely in teams with low to medium cognitive conflict levels. Thus, teams with a combination of high interpersonal conflict and low cognitive conflict were unable to reap the benefits of having high teamwork KSAs. On the other hand, teams that engage in frequent and rich task-focused discussions while maintaining low interpersonal conflict levels are more likely to effectively utilise their teamwork skills during the ideation and planning phases of the entrepreneurial project.

\section{Conclusion}

\subsection{Implications for entrepreneurship education}

This research has several implications for entrepreneurial practice and education. Our findings suggest that new entrepreneurial teams might benefit from selecting team members who excel at teamwork and investing in training interventions focused on developing teamwork competencies. The dimensions outlined by Stevens and Campion (1999) can be used as a guide to design training programs aimed at teamwork skill development (Weber and Funke, 2012). Results from a prior meta-analysis on team training (McEwan et al., 2017) further support the effectiveness of this type of intervention to improve both team competencies and team outcomes. Prior studies that integrate specific teamwork training interventions into entrepreneurship courses reported positive results (Bissola et al., 2017; Boni et al., 2009; Weber and Funke, 2012). 
Entrepreneurship education can benefit from fostering team members' shared understanding and from developing strategies to manage different types of emergent conflict. Our findings suggest that teams can reach higher performance levels if members are skilled at collaboration and establish processes and practise behaviours that promote and channel cognitive conflict while preventing the emergence of relationship conflict. Various methodologies such as the use of business simulators (Maltarich et al., 2018), team contracts and social development of personal connections (Boni et al., 2009), or constructive controversy and reflexivity team training systems (O'Neill et al., 2017) have been successfully applied in entrepreneurship, business or innovation education programs to develop the ability to positively and productively manage conflict. Finally, the crucial role of entrepreneurship educators in this collaborative learning context should be highlighted. Faculty teaching entrepreneurship courses can assume the role of coaches that proactively provide guidance and mentoring to teams so that they can build confidence to work in teams and improve their ability to manage emerging conflict (Boni et al., 2009; Hero and Lindfors, 2019).

\subsection{Limitations and future research directions}

The findings from this study should be interpreted in light of the following limitations, some of which also present future research opportunities. Firstly, using a student sample limits the generalisability of the results to organisational settings as it does not fully capture the emergence and complex nature of new venture teams in the field. Future studies can explore these questions in new venture teams or examine additional contextual factors associated with the business context or the team. Secondly, even if the intra-team conflict measures used in this study are widely used and accepted in the team literature (for example, Pearson et al., 2002), they are based on self-assessment by participants. Thirdly, although this paper examined emerging conflict, there are other emergent states such as cohesion and shared cognition that can influence team outcomes (Chen et al., 2017). It can be of interest to study how the interactions between team competencies and other emergent states impact the performance of entrepreneurial learning teams. Additionally, future research can explore additional metrics that incorporate the team's dynamic nature and interaction and communication through direct observation. Finally, since there is a need for collaborative pedagogical models in entrepreneurial education that help develop entrepreneurial skills (Hägg and Gabrielsson, 2020), future research could further examine how different teambased entrepreneurial learning contexts or specific training approaches can impact the development of teamwork skills and team performance.

\section{References}

Baron, R.A. and Tang, J. (2009), "Entrepreneurs' social skills and new venture performance: mediating mechanisms and cultural generality", Journal of Management, Vol. 35 No. 2, pp. 282-306, doi: 10. 1177/0149206307312513.

Barrick, M.R., Bradley, B.H., Kristof-Brown, A.L. and Colbert, A.E. (2007), "The moderating role of top management team interdependence: implications for real teams and working groups", Academy of Management Journal, Vol. 50 No. 3, pp. 544-557, doi: 10.5465/amj.2007.25525781.

Bauman, A. and Lucy, C. (2019), "Enhancing entrepreneurial education: developing competencies for success", The International Journal of Management Education, Vol. 19 No. 1, p. 100293, doi: 10. 1016/j.ijme.2019.03.005.

Becker, G. (1964), Human Capital, Columbia University Press, New York.

Bell, R. and Bell, H. (2016), "An enterprise opportunity for entrepreneurial students: student enterprise development and experience assessed through the student voice", Education + Training, Vol. 58 Nos 7/8, pp. 751-765, doi: 10.1108/ET-12-2014-0150.

\section{Teamwork competencies and team performance}


ET

64,4

Birdthistle, N., Costin, Y. and Hynes, B. (2016), "Engendering entrepreneurial competencies in the youth of today: a teacher's perspective", Education + Training, Vol. 58 Nos 7/8, pp. 766-782, doi: 10.1108/ET-02-2016-0031.

Bissola, R., Imperatori, B. and Biffi, A. (2017), "A rhizomatic learning process to create collective knowledge in entrepreneurship education: open innovation and collaboration beyond boundaries", Management Learning, Vol. 48 No. 2, pp. 206-226, doi: 10.1177/1350507616672735.

Boni, A.A., Weingart, L.R. and Evenson, S. (2009), "Innovation in an academic setting: designing and leading a business through market-focused, interdisciplinary teams", Academy of Management Learning and Education, Vol. 8 No. 3, pp. 407-417, doi: 10.5465/amle.8.3.zqr407.

Boyle, P.J., Hanlon, D. and Russo, J.E. (2012), “The value of task conflict to group decisions”, Journal of Behavioral Decision Making, Vol. 25 No. 3, pp. 217-227, doi: 10.1002/bdm.725.

Brinckmann, J. and Hoegl, M. (2011), "Effects of initial teamwork capability and initial relational capability on the development of new technology-based firms", Strategic Entrepreneurship Journal, Vol. 5 No. 1, pp. 37-57, doi: 10.1002/sej.106.

Chang, W.L. and Lee, C.Y. (2013), "Virtual team e-leadership: the effects of leadership style and conflict management mode on the online learning performance of students in a business-planning course", British Journal of Educational Technology, Vol. 44 No. 6, pp. 986-999, doi: 10.1111/ bjet.12037.

Chen, G., Donahue, L.M. and Klimoski, R.J. (2004), "Training undergraduates to work in organisational teams", Academy of Management Learning and Education, Vol. 3 No. 1, pp. 27-40, doi: 10.5465/ amle.2004.12436817.

Chen, M.H., Chang, Y.Y. and Chang, Y.C. (2017), "The trinity of entrepreneurial team dynamics: cognition, conflicts and cohesion", International Journal of Entrepreneurial Behavior and Research, Vol. 23 No. 6, pp. 934-951, doi: 10.1108/IJEBR-07-2016-0213.

Chen, S.H., Wang, W.T. and Lu, C.T. (2021), "Exploring the development of entrepreneurial identity in a learning-by-doing entrepreneurial project environment", Education + Training, Vol. 63 No. 5, pp. 679-700, doi: 10.1108/ET-07-2020-0195.

Chwolka, A. and Raith, M.G. (2012), "The value of business planning before start-up-a decisiontheoretical perspective", Journal of Business Venturing, Vol. 27 No. 3, pp. 385-399, doi: 10.1016/j. jbusvent.2011.01.002.

Cohen, A., Doveh, E. and Eick, U. (2001), "Statistical properties of the rWG (J) index of agreement", Psychological Methods, Vol. 6 No. 3, pp. 297-310, doi: 10.1037/1082-989X.6.3.297.

Costa, P.L., Passos, A.M. and Bakker, A.B. (2015), "Direct and contextual influence of team conflict on team resources, teamwork engagement, and team performance", Negotiation and Conflict Management Research, Vol. 8 No. 4, pp. 211-227, doi: 10.1111/ncmr.12061.

De Dreu, C.K. and Weingart, L.R. (2003), "Task versus relationship conflict, team performance, and team member satisfaction: a meta-analysis", Journal of Applied Psychology, Vol. 88 No. 4, pp. 741-749, doi: 10.1037/0021-9010.88.4.741.

De Jong, A., Song, M. and Song, L.Z. (2013), "How lead founder personality affects new venture performance: the mediating role of team conflict", Journal of Management, Vol. 39 No. 7, pp. 1825-1854, doi: 10.1177/0149206311407509.

De Wit, F.R., Greer, L.L. and Jehn, K.A. (2012), “The paradox of intragroup conflict: a meta-analysis”, Journal of Applied Psychology, Vol. 97 No. 2, pp. 360-390, doi: 10.1037/a0024844.

DeChurch, L.A., Mesmer-Magnus, J.R. and Doty, D. (2013), "Moving beyond relationship and task conflict: toward a process-state perspective", Journal of Applied Psychology, Vol. 98 No. 4, pp. 559-578, doi: 10.1037/a0032896.

Doblinger, M. (2022), "Individual competencies for self-managing team performance: a systematic literature review", Small Group Research, Vol. 53 No. 1, pp. 128-180, doi: 10.1177/ 1046496421104111410464964211041114. 
Foo, M.D. (2011), "Teams developing business ideas: how member characteristics and conflict affect member-rated team effectiveness”, Small Business Economics, Vol. 36 No. 1, pp. 33-46, doi: 10.1007/s11187-009-9176-8.

Foo, M.D., Sin, H.P. and Yiong, L.P. (2006), "Effects of team inputs and intrateam processes on perceptions of team viability and member satisfaction in nascent ventures", Strategic Management Journal, Vol. 27 No. 4, pp. 389-399, doi: 10.1002/smj.514.

Hägg, G. and Gabrielsson, J. (2020), "A systematic literature review of the evolution of pedagogy in entrepreneurial education research", International Journal of Entrepreneurial Behavior and Research, Vol. 26 No. 5, pp. 829-861, doi: 10.1108/IJEBR-04-2018-0272.

Harms, R. (2015), "Self-regulated learning, team learning and project performance in entrepreneurship education: learning in a lean start-up environment", Technological Forecasting and Social Change, Vol. 100, pp. 21-28, doi: 10.1016/j.techfore.2015.02.007.

Hayes, A.F. (2018), Introduction to Mediation, Moderation, and Conditional Process Analysis: A Regression-Based Approach, Guilford publications, New York.

Hero, L.M. and Lindfors, E. (2019), "Students' learning experience in a multidisciplinary innovation project", Education + Training, Vol. 61 No. 4, pp. 500-522, doi: 10.1108/ET-06-2018-0138.

Hirschfeld, R.R., Jordan, M.H., Feild, H.S., Giles, W.F. and Armenakis, A.A. (2006), "Becoming team players: team members' mastery of teamwork knowledge as a predictor of team task proficiency and observed teamwork effectiveness", Journal of Applied Psychology, Vol. 91 No. 2, pp. 467-474, doi: 10.1037/0021-9010.91.2.467.

Hoogendoorn, S., Oosterbeek, H. and Van Praag, M. (2013), "The impact of gender diversity on the performance of business teams: evidence from a field experiment", Management Science, Vol. 59 No. 7, pp. 1514-1528, doi: 10.1287/mnsc.1120.1674.

$\mathrm{Hu}, \mathrm{N} ., \mathrm{Wu}, \mathrm{J}$. and Gu, J. (2019), "Cultural intelligence and employees' creative performance: the moderating role of team conflict in inter-organisational teams", Journal of Management and Organization, Vol. 25 No. 1, pp. 96-116, doi: 10.1017/jmo.2016.64.

Hülsheger, U.R., Anderson, N. and Salgado, J.F. (2009), "Team-level predictors of innovation at work: a comprehensive meta-analysis spanning three decades of research", Journal of Applied Psychology, Vol. 94 No. 5, pp. 1128-1145, doi: 10.1037/a0015978.

Huber, L.R., Sloof, R., Van Praag, M. and Parker, S.C. (2020), "Diverse cognitive skills and team performance: a field experiment based on an entrepreneurship education program", Journal of Economic Behavior and Organization, Vol. 177, pp. 569-588, doi: 10.1016/j.jebo.2020.06.030.

Hwang, M.I. (2018), "Relationship between teamwork and team performance: experiences from an ERPsim competition", Journal of Information Systems Education, Vol. 29 No. 3, pp. 157-168.

Jehn, K.A. (1995), "A multimethod examination of the benefits and detriments of intragroup conflict", Administrative Science Quarterly, Vol. 40 No. 2, pp. 256-282, doi: 10.2307/2393638.

Knipfer, K., Schreiner, E., Schmid, E. and Peus, C. (2018), "The performance of pre-founding entrepreneurial teams: the importance of learning and leadership", Applied Psychology, Vol. 67 No. 3, pp. 401-427, doi: 10.1111/apps.12126.

Kolb, D.A. (1984), Experiential Learning: Experience as the Source of Learning and Development, Prentice-Hall, Englewood Cliffs, NJ.

Kollmann, T., Stöckmann, C. and Linstaedt, J.W. (2019), "Task conflict, narcissism and entrepreneurial capability in teams planning a business: a moderated moderation approach to explaining business planning performance", Journal of Small Business Management, Vol. 57 No. 4, pp. 1399-1423, doi: 10.1111/jsbm.12418.

Kozlinska, I., Rebmann, A. and Mets, T. (2020), "Entrepreneurial competencies and employment status of business graduates: the role of experiential entrepreneurship pedagogy", Journal of Small Business and Entrepreneurship. doi: 10.1080/08276331.2020.1821159.

Lackéus, M. (2020), "Comparing the impact of three different experiential approaches to entrepreneurship in education", International Journal of Entrepreneurial Behavior and Research, Vol. 26 No. 5, pp. 937-971, doi: 10.1108/IJEBR-04-2018-0236.

\section{Teamwork competencies and team performance}


ET

64,4

Leach, D.J., Wall, T.D., Rogelberg, S.G. and Jackson, P.R. (2005), “Team Autonomy, performance, and member job strain: uncovering the teamwork KSA link", Applied Psychology: An International Review, Vol. 54 No. 1, pp. 1-24, doi: 10.1111/j.1464-0597.2005.00193.x.

Leffel, A., Hallam, C. and Darling, J. (2016), "Enhancement of entrepreneurial leadership: a case focusing on a model of successful conflict management skills", Administrative Issues Journal: Connecting Education, Practice, and Research, Vol. 2 No. 2, pp. 13-25, doi: 10.5929/2012.2.2.2.2.

Maltarich, M.A., Kukenberger, M., Reilly, G. and Mathieu, J. (2018), "Conflict in teams: modeling early and late conflict states and the interactive effects of conflict processes", Group and Organization Management, Vol. 43 No. 1, pp. 6-37, doi: 10.1177/1059601116681127.

Mandel, R. and Noyes, E. (2016), "Survey of experiential entrepreneurship education offerings among top undergraduate entrepreneurship programs", Education + Training, Vol. 58 No. 2, pp. 164-178, doi: 10.1108/ET-06-2014-0067.

Martínez-Moreno, E., González-Navarro, P., Zornoza, A. and Ripoll, P. (2009), "Relationship, task and process conflicts on team performance", International Journal of Conflict Management, Vol. 20 No. 3, pp. 251-268, doi: 10.1108/10444060910974876.

Mathieu, J.E., Tannenbaum, S.I., Donsbach, J.S. and Alliger, G.M. (2014), "A review and integration of team composition models: moving toward a dynamic and temporal framework", Journal of Management, Vol. 40 No. 1, pp. 130-160, doi: 10.1177/0149206313503014.

Mazra, M. (2017), "Entrepreneurial team diversity and new venture performance in Cameroon: the moderating effect of conflicts", International Journal of Innovation Management, Vol. 21 No. 4, pp. 1-22, doi: 10.1142/S1363919617500384.

McClough, A.C. and Rogelberg, S.G. (2003), "Selection in teams: an exploration of the teamwork knowledge, skills, and ability test", International Journal of Selection and Assessment, Vol. 11 No. 1, pp. 56-66, doi: 10.1111/1468-2389.00226.

McEwan, D., Ruissen, G.R., Eys, M.A., Zumbo, B.D. and Beauchamp, M.R. (2017), “The effectiveness of teamwork training on teamwork behaviours and team performance: a systematic review and meta-analysis of controlled interventions", PLoS One, Vol. 12 No. 1, pp. 1-23, doi: 10.1371/ journal.pone.0169604.

Miller, D.L. (2001), "Reexamining teamwork KSAs and team performance", Small Group Research, Vol. 32 No. 6, pp. 745-766, doi: 10.1177/104649640103200604.

Mitchell, R., Boyle, B. and Von Stieglitz, S. (2019), "Professional commitment and team effectiveness: a moderated mediation investigation of cognitive diversity and task conflict", Journal of Business and Psychology, Vol. 34 No. 4, pp. 471-483, doi: 10.1007/s10869-018-9550-0.

Morland, L., Scott, J.M. and Thompson, J.L. (2021), "Experiential entrepreneurship education and the student-focused entrepreneurial university", Education + Training, Vol. 63 No. 9, pp. 1258-1275, doi: 10.1108/ET-09-2020-0259.

Neumeyer, X. and Santos, S.C. (2020), "A lot of different flowers make a bouquet: the effect of gender composition on technology-based entrepreneurial student teams", International Entrepreneurship and Management Journal, Vol. 16 No. 1, pp. 93-114, doi: 10.1007/s11365019-00603-7.

O'Neill, T.A., Allen, N.J. and Hastings, S.E. (2013), "Examining the 'pros' and 'cons' of team conflict: a team-level meta-analysis of task, relationship, and process conflict", Human Performance, Vol. 26 No. 3, pp. 236-260, doi: 10.1080/08959285.2013.795573.

O’Neill, T.A., Hoffart, G.C., McLarnon, M.M., Woodley, H.J., Eggermont, M., Rosehart, W. and Brennan, R. (2017), "Constructive controversy and reflexivity training promotes effective conflict profiles and team functioning in student learning teams", Academy of Management Learning and Education, Vol. 16 No. 2, pp. 257-276, doi: 10.5465/amle.2015.0183.

Pearson, A.W., Ensley, M.D. and Amason, A.C. (2002), “An assessment and refinement of Jehn's intragroup conflict scale", International Journal of Conflict Management, Vol. 13 No. 2, pp. 110-126, doi: 10.1108/eb022870. 
Peschl, H., Deng, C. and Larson, N. (2021), "Entrepreneurial thinking: a signature pedagogy for an uncertain 21st century", The International Journal of Management Education, Vol. 19 No. 1, doi: 10.1016/j.ijme.2020.100427.

Pittaway, L. and Cope, J. (2007), "Simulating entrepreneurial learning: integrating experiential and collaborative approaches to learning”, Management Learning, Vol. 38 No. 2, pp. 211-233, doi: 10.1177/1350507607075776.

Podsakoff, P.M., MacKenzie, S.B., Lee, J.Y. and Podsakoff, N.P. (2003), "Common method biases in behavioral research: a critical review of the literature and recommended remedies", Journal of Applied Psychology, Vol. 88 No. 5, pp. 879-903, doi: 10.1037/0021-9010.88.5.879.

Porath, C.L. and Erez, A. (2007), "Does rudeness really matter? The effects of rudeness on task performance and helpfulness", Academy of Management Journal, Vol. 50 No. 5, pp. 1181-1197, doi: 10.5465/amj.2007.20159919.

Salas, E., Reyes, D.L. and McDaniel, S.H. (2018), "The science of teamwork: progress, reflections, and the road ahead", American Psychologist, Vol. 73 No. 4, pp. 593-600, doi: 10.1037/amp0000334.

Shaw, J.D., Zhu, J., Duffy, M.K., Scott, K.L., Shih, H.A. and Susanto, E. (2011), "A contingency model of conflict and team effectiveness”, Journal of Applied Psychology, Vol. 96 No. 2, pp. 391-400, doi: 10.1037/a0021340.

Sorrel, M.A., Olea, J., Abad, F.J., de la Torre, J., Aguado, D. and Lievens, F. (2016), "Validity and reliability of situational judgement test scores: a new approach based on cognitive diagnosis models", Organizational Research Methods, Vol. 19 No. 3, pp. 506-532, doi: 10.1177/ 1094428116630065.

Stevens, M.J. and Campion, M.A. (1999), "Staffing work teams: development and validation of a selection test for teamwork settings", Journal of Management, Vol. 25 No. 2, pp. 207-228, doi: 10.1016/S0149-2063(99)80010-5.

Stevens, M.J., Jones, R.G. and Fisher, D.L. (2002), "What's past is prologue: exploring a biodata approach to team selection”, in Morgeson, F.P. (chair) (Ed.), Selection for teams: A tale of five approaches, Symposium at the 17th Annual Meeting of the Society for Organizational and Industrial Psychology, Toronto.

Tasa, K., Taggar, S. and Seijts, G.H. (2007), "The development of collective efficacy in teams: a multilevel and longitudinal perspective", Journal of Applied Psychology, Vol. 92 No. 1, pp. 17-27, doi: 10.1037/0021-9010.92.1.17.

Wang, W.T., Lai, W.Y. and Lu, C.T. (2019), "Learning from others via team conflicts: exploring the impact of individual entrepreneurial characteristics on the construction of entrepreneurial identity", International Journal of Entrepreneurial Behavior and Research, Vol. 26 No. 2, pp. 373-396, doi: 10.1108/IJEBR-10-2018-0667.

Weber, S. and Funke, S. (2012), “An 'instructional' perspective on entrepreneurship education-focusing on the development of team competencies", Empirical Research in Vocational Education and Training, Vol. 4 No. 1, pp. 49-72, doi: 10.1007/BF03546507.

Zhou, Z. and Verburg, R. (2020), "Open for business: the impact of creative team environment and innovative behaviour in technology-based start-ups", International Small Business Journal: Researching Entrepreneurship, Vol. 38 No. 4, pp. 318-336, doi: 10.1177/0266242619892793.

\section{Corresponding author}

María José González-López can be contacted at:mglopez@ugr.es

For instructions on how to order reprints of this article, please visit our website:

www.emeraldgrouppublishing.com/licensing/reprints.htm

Or contact us for further details: permissions@emeraldinsight.com 